\title{
O futuro da Sociologia Rural e sua contribuição para a qualidade de vida rural ${ }^{*}$
}

\author{
JOSÉ DE SOUZA MARTINS
}

\begin{abstract}
A SOCIOLOGIA RURAL tem um pesado débito para com as populações rurais de todo o mundo. As gerações vitimadas por uma sociologia a serviço da difusão de inovações, cuja prioridade era a própria inovação, ainda estão aí, legando aos filhos que chegam à idade adulta os efeitos de uma demolição cultural que nem sempre foi substituída por valores sociais includentes, emancipadores e libertadores: ou legando aos filhos o débito social do desenraizamento e da migração para as cidades ou para as vilas pobres próximas das grandes fazendas de onde saíram, deslocados que foram para cenários de poucas oportunidades e de nenhuma qualidade de vida.
\end{abstract}

Porque essa é, certamente, uma preocupação de todos nós, especialmente de minha geração, gostaria de colocar no centro desta reflexão o tema do desencontro entre a sociologia rural e as populações rurais a cujo estudo se dedica. E gostaria de fazê-lo assinalando que, para a sociologia rural, as últimas décadas foram décadas de seu próprio desencantamento.

Ao se tornar instrumento do desencantamento do mundo - de que nos fala Max Weber - a sociologia rural desencantou-se a si mesma, ao descobrir lentamente que as populações rurais têm seus próprios códigos de conhecimento e sua própria concepção de destino, que são tão legítimos quanto os códigos e as concepções dos setores da sociedade dos quais os sociólogos se sentem mais próximos e mais acolhidos. Nenhum campo da sociologia ficou mais exposto a esse desencantamento do que a sociologia rural. Porque nenhum ficou tão obstinadamente preso à suposição de que as populações rurais são populações retardatárias do desenvolvimento econômico e da História, supostas ilhas de primitivismo no suposto paraíso da modernidade. Diferentes concepções de sociologia rural defrontaram-se com a mesma dificuldade.

* Exposição feita pelo autor em plenário, na sessão de encerramento do X Congresso Mundial de Sociologia Rural, realizado no Rio de Janeiro em 4 de agosto de 2000. 
Por muito tempo e para muitos, a sociologia rural foi mais uma sociologia da ocupação agrícola e da produtividade do que uma sociologia propriamente rural. Mais uma sociologia das perturbações do agrícola pelo rural do que uma sociologia de um modo de ser e de um modo de viver mediados por uma maneira singular de inserção nos processos sociais e no processo histórico. Não raro, o mundo rural tornou-se objeto de estudo e de interesse dos sociólogos rurais pelo "lado negativo", por aquilo que parecia incongruente com as fantasias da modernidade. Não por aquilo que as populações rurais eram e sim pelo que os sociólogos gostariam que elas fossem.

Quando assumiu o mundo rural como objeto, a sociologia rural o fez mais como "adversária" do que como ciência isenta e neutra. Mais como ciência da modernização do que como ciência aberta à compreensão dos efeitos destrutivos e perversos que não raro a modernização acarreta. A modernização é um valor dos sociólogos rurais e não necessariamente das populações rurais, porque, de fato, para estas não raro ela tem representado desemprego, desenraizamento, desagregação da família e da comunidade, dor e sofrimento.

O deslocamento de grandes massas rurais para a cidade revelou-nos uma dimensão desdenhada do mundo rural: um modo de ser, uma visão de mundo e uma perspectiva crítica poderosa em relação ao desenvolvimento capitalista, à modernização anômala e à desumanização das pessoas apanhadas de modo anômico, incompleto e marginal pelas grandes transformações econômicas e políticas que, não raro, tiveram os sociólogos como acólitos. O deslocamento nos mostrou, e já há estudos sobre o fenômeno, que o rural pode subsistir culturalmente por longo tempo fora da economia agrícola. Pode subsistir como visão de mundo, como nostalgia criativa e autodefensiva, como moralidade em ambientes moralmente degradados das grandes cidades, como criatividade e estratégia de vida numa transição que já não se cumpre conforme as profecias dos sociólogos. Essa transição é antes inconclusa passagem, um transitório que permanece, uma promessa de bem-estar que não se confirma, uma espécie de agonia sem fim.

A sociologia rural, sabemos todos, foi engolida por um compromisso precipitado com a soi disant modernização econômica, no equivocado pressuposto de que essa modernização acarretaria automaticamente a modernização social e o bem-estar das populações rurais ou ruralizadas. Foi necessária muita coragem, muito atrevimento cívico, à custa de muita marginalização, para que sociólogos rurais desafiassem esse compromisso, expusessem suas irracionalidades e reconhecessem no mundo rural um mundo de criatividade, de inovação e luta contra as aberrações econômicas, políticas e mesmo acadêmicas que vitimam suas populações.

Desde os anos 70 a modernização forçada do campo e o desenvolvimento econômico tendencioso e excludente nos vêm mostrando que esse modelo imperante de desenvolvimento acarretou um contradesenvolvimento social 
responsável por formas perversas de miséria antes desconhecidas em muitas partes do mundo. As favelas e cortiços desta nossa América Latina, e de outras partes, constituem enclaves rurais no mundo urbano, transições intransitivas, desumanos modos de sobreviver mais do que de viver. O mundo rural está também aí, como resíduo, como resto da modernização forçada e forçadamente acelerada, que introduziu na vida das populações do campo um ritmo de transformação social e econômica gerador de problemas sociais que o próprio sistema em seu conjunto não tem como remediar.

No geral, debita-se na conta de uma suposta e nunca comprovada resistência das populações rurais para a mudança e a modernização a responsabilidade por esse desastre social. Essa resistência, ficou evidente, era resistência ao que para elas não tinha o menor sentido e não podia, portanto, ser compreendido. A culpa, no fim das contas, é da vítima.

Aqui no Brasil, tivemos, nos anos 80 e 90, a grande expansão territorial do grande capital moderno que foi o da expansão da fronteira agropecuária na Amazônia. Espaços ocupados por populações indígenas, que muitas vezes jamais haviam tido contato com o homem branco, e por populações camponesas pobres remanescentes das ondas de povoamento dos séculos XVIII e XIX, foram declarados espaços vazios pelo Estado nacional. Estímulos fiscais escandalosos foram concedidos a ricos grupos econômicos, nacionais e estrangeiros, para que fizessem uma ocupação moderna do território. Uma modernização postiça, pesadamente subvencionada pela sociedade brasileira, mais expressão da ineficiência da grande empresa do que de sua louvada eficiência.

Os cientistas sociais deste país, e muitos estrangeiros que para aqui vieram a fim de estudar e acompanhar o deslocamento da fronteira econômica na região amazônica, testemunharam e documentaram uma das grandes falácias da sociologia rural, a da função emancipadora da modernização técnica e econômica. As grandes empresas recorreram ao trabalho escravo, à peonagem, à escravidão por dívida, para efetivar a implantação de megaprojetos agropecuários. Invariavelmente usando pistoleiros para torturar, perseguir, violentar e matar os que tentavam fugir.

Alguns desses projetos são de grande sofisticação tecnológica, como o da Fazenda Vale do Rio Cristalino, que foi implantado pela empresa alemã Volkswagen. O plano previa criação e abate de gado, que seria refrigerado no vôo entre a fazenda e a Alemanha, dispensando a instalação de frigoríficos. Minúsculos artefatos eletrônicos eram implantados no gado para permitir seu controle à distância, por satélite, e determinar providências sanitárias e o momento próprio do abate. Mas, na fazenda havia 500 trabalhadores escravizados. Pesquisadores estimam que na década de 70 mais de meio milhão de trabalhadores foram submetidos à escravidão na região amazônica para permitir a abertura das novas e modernas empresas agropecuárias. Foi esse um retrocesso histórico espantoso em nome da modernização econômica e tecnológica. 
Não só aqui esses fatos têm acontecido. Na Junta de Curadores do Fundo Voluntário das Nações Unidas contra as Formas Contemporâneas de Escravidão (The Board of Trustees of the UN Voluntary Fund on the Contemporary Forms of Slavery), de que sou membro, temos recebido pedidos de socorro e denúncias de escravidão no mundo inteiro. Estamos trabalhando com a hipótese, baseados em dados da Antislavery International, de que há no mundo hoje 200 milhões de escravos. Todos vitimados pela decomposição do mundo rural que resultou de intervenções de "engenharia social" modernizadora, intervenções que, infelizmente, não inocentam a sociologia rural.

Sabemos todos que a sociologia rural, a pretexto de se tornar uma força auxiliar da modernização e da remoção das resistências sociais à mudança, contribuiu abertamente para a violação de modos de vida e visões de mundo e de culturas tradicionais em que a pobreza, ao menos, revestia-se de padrões sociais de dignidade toleráveis. Onde a modernização rural forçada fracassou, como ocorre em amplas regiões e situações desta América Latina, da Ásia e da África, as velhas estruturas sociais foram desmanteladas, as instituições corroídas, as comunidades desorganizadas, os costumes desmoralizados e a população degradada. Foi ela lançada impiedosamente na cloaca da civilização e do desenvolvimento e da modernização excludentes que beneficiaram apenas parte da sociedade, privando do benefício milhões de vítimas inocentes. A sociologia rural tinha elaborados diagnósticos para desmontar a sociedade tradicional, mas não tinha condições de diagnosticar e solucionar os graves problemas sociais que não previu e que decorreriam dos processos sociais anômicos que involuntariamente estimulou, sugeriu, apoiou ou promoveu.

O futuro da sociologia rural depende de que reconheçamos, antes de tudo, que a nossa disciplina contribuiu para privar de futuro parcelas ponderáveis da população do Terceiro Mundo. Não se trata de pedir à nossa profissão e à nossa disciplina que faça um mea culpa tão em moda na hipocrisia contemporânea. Trata-se de pedir que façamos uma revisão crítica corajosa dos rumos dominantes na sociologia rural por longos anos, que nos dediquemos, também, a uma sociologia da sociologia rural para compreender o grande desencontro entre essa disciplina e a sociedade que ela deve compreender e explicar.

É preciso transgredir as imunidades estamentais e corporativas de que a sociologia rural se cercou, fazê-la dialogar mais, comungar mais e aprender mais com a História, a Literatura, a Geografia, a Antropologia. Há mais sociologia rural de alto refinamento em obras de Gabriel Garcia Marquez, Manuel Scorza, John Steinbeck, José Saramago, Juan Rulfo ou Guimarães Rosa do que em muitas de nossas análises complexas e elaboradas.

É preciso fazer mais e insistentemente com a sociologia rural o que é próprio da sociologia: objeto de uma sociologia do conhecimento, uma sociologia crítica que nos permita remover compromissos que dela fazem um instrumento da 
economia e da "engenharia social", remover empecilhos que ainda subsistem a que se torne um instrumento da dignidade humana e da libertação do homem de suas carências e misérias. As populações rurais, mais do que instrumentos da produção agrícola, são autoras e consumadoras de um modo de vida que é também um poderoso referencial de compreensão das irracionalidades e contradições que existem fora do mundo rural. São uma reserva importante de um tipo de inovação e criatividade que tende a ser destruído e que pode desaparecer.

O futuro da sociologia rural depende do futuro das populações rurais. O futuro da sociologia rural depende, também, e muito, de que ela se liberte de uma concepção estamental do mundo rural, que em muitos estudos sociológicos, e reconheça-se, não de sociólogos rurais, aparece como um mundo degradado, um mundo pária e irrelevante, lugar do nada, lugar de uma humanidade residual destituída de competência histórica para afirmar-se como sujeito social e como sujeito de seu próprio destino.

A sociologia rural acumulou poderosos conhecimentos sobre as contradições sociais que alcançam de modo mais destrutivo as populações rurais. Os sociólogos rurais podem assumir corajosamente a grande missão da ciência que é servir ao Homem para libertá-lo daquilo que tolhe a sua humanização. E não são poucos que o tem feito na pesquisa marcada por profunda inquietação ética e ampla competência teórica para diagnosticar problemas e descobrir alternativas nas próprias concepções e relações sociais dos grupos humanos que estudam.

As próprias populações rurais vitimadas pelo desenvolvimento econômico excludente, que todos testemunhamos, têm procurado seu próprio rumo, têm se alçado acima da indignidade que as vitima, têm proclamado seus direitos e têm questionado os responsáveis por sua situação. Os movimentos sociais do campo são a forma do protesto dos pobres da terra, o clamor dos sem voz porque não foram ouvidos no devido tempo. Eles desafiam a sociologia rural a compreender o protagonismo e a criatividade das populações rurais e a compreender também as saídas possíveis das situações socialmente anômicas em que muitas vezes se encontram.

O futuro da sociologia rural não depende do que ela tenha a propor quanto à qualidade de vida rural. $\mathrm{O}$ futuro da sociologia rural depende amplamente do que as populações rurais tenham a lhe propor para que essa qualidade de vida seja incrementada; e do que os sociólogos rurais estejam dispostos generosamente a oferecer-lhes. Esse futuro depende amplamente do deciframento e da superação dos enigmas que as perturbam, da compreensão dos processos sociais que as desagregam e as marginalizam e que, por isso, precisam compreender e vencer para que tenham a qualidade de vida a que têm direito. Para ensinar, a sociologia rural precisa aprender. Para compreender sociologicamente, o sociólogo rural precisa reconhecer-se como membro da comunidade de destino das populações que estuda. 
Para não parecer excessivamente severo, convém reconhecer que os equívocos históricos da sociologia rural vêm de sua maior virtude, dentre as muitas virtudes que há no conhecimento especializado que ela tem propiciado sobre o mundo rural. Nela o valor fundante está na transformação social, na superação de problemas e bloqueios sociais ao desenvolvimento. Prefiro interpretar esse compromisso extracientífico da sociologia rural como um compromisso com os fins da mudança, com os resultados das inovações e não com a própria inovação, o que muitos em nossa comunidade profissional têm assinalado e concretizado.

A sociologia rural poderá contribuir para melhorar a qualidade de vida das populações rurais e recuperar a dimensão crítica da tradição sociológica, se puder ver-se criticamente na relação investigativa e na relação educativa com as populações que estuda. Se abrir mão de suas certezas para assimilar as incertezas que ajudou a disseminar e fazer dessas incertezas uma mediação cognitiva essencial na relação entre a teoria e a prática.

Na reconciliação com a tradição sociológica clássica e seu compromisso com os benefícios sociais das grandes transformações, a sociologia rural poderá se encontrar também, ainda que criticamente, como é necessário na ciência, com os movimentos sociais que nos falam do novo protagonismo histórico das populações rurais, de sua busca. A contribuição possível da sociologia rural para a qualidade de vida rural está justamente no reconhecimento das reservas de possibilidade histórica que as populações rurais, sobretudo as populações camponesas, ainda têm para reinventar o mundo e reinventar-se no mundo.

O futuro da sociologia rural e sua contribuição para a qualidade de vida rural dependem de que ela, nos ainda tortuosos e pedregosos caminhos desse mundo rural desprezado e desdenhado, empobrecido e ameaçado, se encontre com a Esperança que em suas pedras há. Porque só pode haver qualidade de vida para diferentes populações se para elas houver, também, lugar para o sonho e a Esperança. O desafio dos sociólogos rurais, numa proposta de compromisso como a do tema destas falas, é o de mergulhar no sonho inventivo e regenerador que ainda há no mundo rural. Tanto para decifrá-lo e prezá-lo, quanto porque há nele a nostalgia do futuro e a negação das privações que o presente representa para muitos.

José de Souza Martins é professor titular de Sociologia da Faculdade de Filosofia, Letras e Ciências Humanas da Universidade de São Paulo; fellow de Trinity Hall e professor titular da Cátedra Simón Bolivar da Universidade de Cambridge (1993-94); membro da Junta de Curadores do Fundo Voluntário das Nações Unidas contra as Formas Contemporâneas de Escravidão. Dentre outros livros, autor de Reforma Agrária - o impossível diálogo, São Paulo, Edusp, 2000. 